\title{
Sb-Sn (Antimony-Tin)
}

\section{H. Okamoto}

The Sb-Sn phase diagram in [Massalski2] was redrawn from [1971Pre].

This phase diagram was updated experimentally and theoretically by [1995Oht], as introduced by [1998Oka]. [2008Man] also got a similar result by thermodynamic modeling.

Figure 1 shows the $\mathrm{Sb}-\mathrm{Sn}$ phase diagram proposed by [2008Che]. The phase diagram was determined by thermodynamic modeling based on experimental data available in the literature supplemented by their own DTA, micrograph, and $\mathrm{x}$-ray diffraction data.

This phase diagram differs from the earlier ones most noticeably with regard to the $\mathrm{Sb}_{2} \mathrm{Sn}_{3}$ phase. In [Massalski2], this phase exists only in a limited temperature range $(\sim 250$ $320{ }^{\circ} \mathrm{C}$ ). This phase exists at 57 at.\% Sn, not at the stoichiometric composition. Its crystal structure is still unknown.

[1997Vas] doubted the existence of the $\beta$ phase having a broad solubility range and proposed the existence of three stoichiometric phases in this system at 34,48 , and probably 50 at.\% Sn. There has been no supporting report on this feature since then.

\section{References}

1971Pre: B. Predel and W. Schwermann, Constitution and Thermodynamics of the Antimony-Tin System, J. Inst. Met., 1971, 99, p 169-173

1995Oht: H. Ohtani, K. Okuda, and K. Ishida, Thermodynamic Study of Phase Equilibria in the $\mathrm{Pb}-\mathrm{Sn}$-Sb System, J. Phase Equilib., 1995, 16(6), p 416-429

1997Vas: V. Vassiliev, M. Lelaurain, and J. Hertz, A New Proposal for the Binary $(\mathrm{Sn}, \mathrm{Sb})$ Phase Diagram and Its Thermodynamic Properties Based on a New e.m.f. Study, J. Alloys Compd., 1997, 247, p 223-233

1998Oka: H. Okamoto, Sb-Sn (Antimony-Tin), J. Phase Equilib., 1998, 19(3), p 292

2008Che: S. Chen, C. Chen, W. Gierlotka, A. Zi, P. Chen, and H. $\mathrm{Wu}$, Phase Equilibria of the Sn-Sb Binary System, J. Electron. Mater, 2008, 37(7), p 992-1002

2008Man: D. Manasijević, J. Vřešt'ál, D. Minić, A. Kroupa, D. Živković, and Ž. Živković, Experimental Investigation and Thermodynamic Description of the In-Sb-Sn Ternary System, J. Alloys Compd., 2008, 450, p 193-199

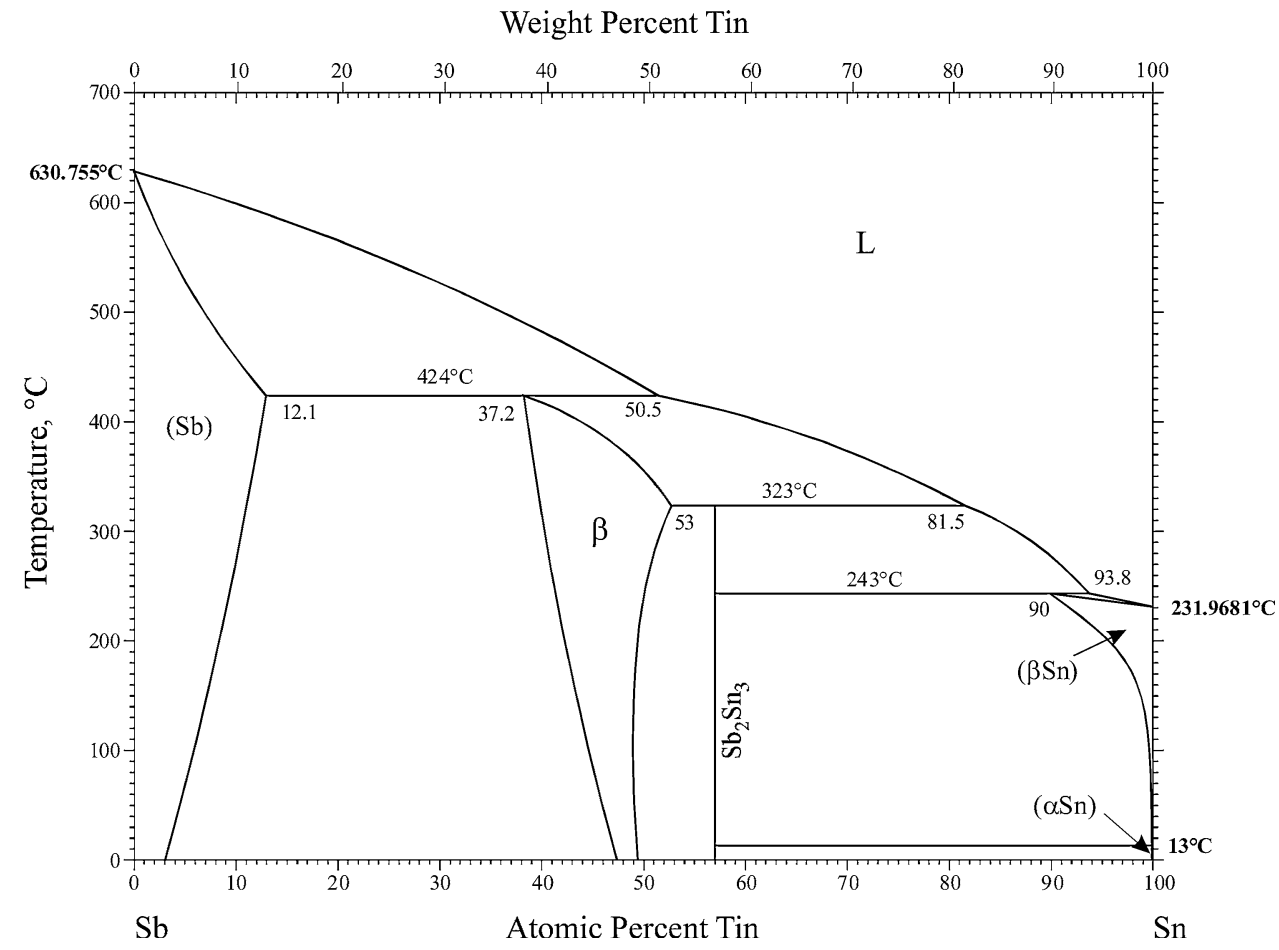

Fig. 1 Sb-Sn phase diagram 